\title{
Modifiable risk factors for non-communicable diseases among medical and non-medical University students in Dar es Salaam, Tanzania: A cross sectional study
}

\section{Suddeys Abdulbasat}

Muhimbili University of Health and Allied Sciences

Method Kazaura ( $\nabla$ methodkazaura@gmail.com )

Muhimbili University of Health and Allied Sciences School of Public Health and Social Sciences https://orcid.org/0000-0003-1246-7161

\section{Research article}

Keywords: Non-communicable diseases, Modifiable risk factor, STEPS survey, Undergraduates

Posted Date: March 2nd, 2020

DOI: https://doi.org/10.21203/rs.3.rs-15669/v1

License: (c) (1) This work is licensed under a Creative Commons Attribution 4.0 International License. Read Full License 


\section{Abstract}

Background: Currently, non-communicable diseases (NCDs) are among the global health problems accounting for more than $70 \%$ of deaths. Yet, healthcare, workers, university and college students who are key educators to the public are at high risk of NCDs. The objective of this study was to assess modifiable risk factors for NCDs among medical and non-medical university students in Dar es Salaam, Tanzania.

Methods: A cross-sectional study included respondents from six universities; split equally between medical and non-medical programmes. From universities with medical programmes, we randomly selected students in clinical track. We administered a modified WHO STEP-1 questionnaire to collect data on modifiable risk factors of NCDs.

Results: A total of 574 students participated in the study. Of these, 315 (54.9\%) undergraduates were in medical programmes. Few, 7 (3.1\%), of the non-medical undergraduates and $14(4.7 \%)$ of the nonmedical undergraduates had none of the NCDs risk factors. The proportion of harmful alcohol consumption among medical and non-medical university students was $15(4.8 \%)$ and $6(2.3 \%)$ respectively. Students reporting sedentary lifestyle was significantly $(p<0.01)$ higher among non-medical undergraduates, 97 (37.5\%), as compared to $82(31.2 \%)$ students in non-medical universities. Undergraduates in non-medical programmes have 10\% significantly increased prevalence ratio of high modifiable risk as compared to medical university students, (aPR=1.1, 95\% Cl: $1.0-1.2)$ independent of age and sex.

Conclusion: Tobacco and armful alcohol consumption among students in medical and non-medical universities is low. Reported physical inactivity and unhealthy diet are high. We suggest broader communication strategies targeting university students in medical and non-medical programmes on dangers of NCDs and awareness of their modifiable risk factors.

\section{Background}

Non-communicable diseases (NCDs) refer to chronic conditions which cannot be transmitted from one person to the other. They result from a combination of genetic, physiological, environmental and behavioral factors [1]. In sub-Sahara African morbidity and mortality from infectious diseases are higher than the NCDs but due to the rising scourge of the latter, WHO estimates that by 2030, NCDs will be the leading cause of mortality in the continent [2].

World Health Organization (WHO) categorizes risk factors for NCDs into two major branches: (a) behavioural and (b) physiological factors. The modifiable risk factors also known as behavioural risk factors constitute of four key behaviours that lead to metabolic changes from which failure to control may result into NCDs. The four main modifiable factors are tobacco use, harmful alcohol consumption, unhealthy diet and physical inactivity [3]. 
Although literature on NCDs in many developing countries is scanty, there have been two WHO-guided surveys in Tanzania on non-communicable diseases and their risk factors. The first survey was conducted in 2011 in Zanzibar and the second was in 2012 in Tanzania mainland. In both surveys, the majority of the population had one or more risk factors for NCDs. More than $95 \%$ of the population consumed less than 5 servings per day of fruits and/or vegetables. Furthermore, almost $30 \%$ and Tanzania mainland and $2 \%$ of the Zanzibar populations were taking alcohol. Inadequate physical activity was between $80 \%$ and $95 \%$ in Mainland Tanzania in Zanzibar. The proportion of smokers was more than $7 \%$ in Zanzibar and about $16 \%$ in Tanzania Mainland $[4,5]$.

Behaviours and general practices of healthcare workers (HCWs) on NCDs do not deviate too far from those of the general population [6]. On one hand, HCWs are perceived by the majority to be the frontline in educating and providing healthcare services. On the other hand, individuals consider them to be a mirror of their practices. Studies have demonstrated patients receiving appropriate counselling on healthy behaviours were dependent on health workers attitudes and behaviour [7].

Crafting of healthcare providers and other medical professionals is higher in learning institutions like the universities [8]. In these institutions, medical students are trained to gain understanding of both the aetiology of diseases and factors involved. They also get experiences from direct contact and consultation with patients suffering from different morbidities including NCDs. In this process, a positive change in behaviour is expected. It is therefore important to address how theoretical and clinical knowledge and practice affect student's habits in relation to control NCDs. Some studies suggest that medical students have low levels of knowledge on specific risk factors and recommendations pertaining to NCD prevention. And, other studies point to larger proportion of these students having greater risk factors of NCDs when compared to the general population $[9,10]$. This is very important because unhealthy habits in universities and colleges may persist even beyond towards adult life [11].

On one hand, the public assumes that HCWs are too knowledgeable on NCDs, but on the other, there are studies that show medical students, physicians and other healthcare workers having similar or even increased modifiable risk factors for NCDs. This contradiction indicates a variance between knowledge and practices towards preventative practices, such as obesity among physicians, risky and harmful alcohol use, low level of physical activity and poor intake of fruits and vegetables $[9,12-20]$.

University students are expected leaders in the future. Whatever they are doing now, could be a mirror of the entire population. Unfortunately, like in many other sub-Saharan countries, Tanzania has limited literature on burden of modifiable risk factors of NCDs among University students. Since we consider university students in medical programmes having more exposure on practices against NCDs, in this study we also aim to compare modifiable risk factors of NCDs among medical and non-medical university students in Dar es salaam, Tanzania.

\section{Methodology}


A cross sectional study was conducted among the medical and non-medical undergraduate University students in Dar es Salaam, Tanzania. There are 12 public and private universities/colleges in Dar es Salaam, four having medical training. The population of undergraduates in medical universities/colleges is about 5,000 and about 23,000 in non-medical universities/colleges.

\section{Sample size and sampling}

We estimated a sample of about 300 undergraduates for each group, medical and non-medical university/college students. We applied a multi-sampling strategy to get the study population. In the first stage, from the four medical university universities/colleges, we randomly selected three. We also randomly selected three out of 11 non-medical universities/colleges. In the second stage, in each selected university/college, we randomly selected relevant strata based on the year of enrolment. In Tanzania, all undergraduates in medical programmes last for five years. We excluded first and second year medical students because of the least exposure to medical training. Therefore, strata were students in their $3^{\text {rd }}, 4^{\text {th }}$ and $5^{\text {th }}$ year of study. For non-medical universities/colleges, most of their programmes last for up to four years. Therefore, strata were the first through fourth year programmes. The required sample size for each group was spread equally to the available strata in each of the selected university/college. In all groups, we excluded undergraduates from abroad because of possible previous training on NCDs. We also excluded students from other health related courses which involved direct provider to patient interaction such as pharmacy and nursing programmes.

\section{Data collection instruments}

We used a self-administered the WHO STEPS (STEPwise approach to Surveillance) data collection tool on NCDs risk factors [21]. Although the general tool has three steps, we used STEP-I that entirely focuses on assessing modifiable risk factors through interviews. The tool was slightly modified to enhance better understanding of the study terms. The tool included structured questions organized into two main sections: (a) the background (social and demographic) information and (b) exposure to the five risky behaviours related to NCDs (tobacco use, alcohol consumption, unhealthy diet, salt intake and physical inactivity). The tool was organized and administered in English. Consenting participants were left with the tool to fill-in for about one week, and then we collected filled-in questionnaires for processing and analysis.

\section{Study variables and measurements}

\section{Tobacco use:}

Tobacco use was defined as those smoking cigarettes, shisha, cigars, nicotine "vaping" instruments or hand rolled cigarettes either. Smokers were either current (within 12 months) or previously (life-time). 
Harmful alcohol consumption:

Alcohol users were those reporting consuming alcohol and heavy episodic drinking was classified as consumption of 6 or more alcoholic drinks in one sitting. One standard alcoholic drink was regarded as consuming a $300 \mathrm{ml}$ bottle of regular beer, $30 \mathrm{ml}$ of spirits or $120 \mathrm{ml}$ glass of wine. Any undergraduate drinking alcohol within 30 days before the date of data collection was considered a current alcohol user.

\section{Unhealthy diet.}

The proxy marker of unhealthy diet was inadequate vegetables and fruits in a typical week. One serving of vegetables was considered similar to a handful of leafy vegetables or three tablespoons of kidney beans or peas or boiled maize. One serving of fruit was considered similar to one mid-sized banana or orange or mango or a handful of grapes or similar fruits. Total fruit and vegetable consumption was computed as the sum of the average intake of vegetables and fruits per day.

\section{Salt intake:}

Salt intake was classified as good (responded affirmatively to more than 3 measures of lowering intake), poor control (1-3 specific salt control measures) and otherwise, no control.

\section{Physical inactivity.}

Physical inactivity also here referred to as sedentary life was computed as the sum of the total activityminutes for work and recreational activities per week. Inactivity was defined as fewer than 75 minutes of vigorous or intensity activity or 150 minutes of moderate intensity physical activity per week.

\section{High risk factors for NCDs}

An undergraduate with at least two of the five risky NCDs factors was categorized high risk.

\section{Statistical analysis}

Collected data were entered into statistical software (Statistical Package for Social Sciences). They were checked for consistency and coverage before commencing the analysis. We summarized data by running frequencies for categorical variables and calculated the means or median with standard deviations or inter-quartile ranges respectively for quantitative variables. We assessed the association between the outcome variables and selected independent variables using Pearson's Chi-Square test. Since the proportion of undergraduates with high risk behaviours for NCDs was higher than $10 \%$, use used Poisson regression analysis to estimate the effect of type of university/college when predicting high risk level. We calculated $95 \%$ confidence intervals as a measure of strength of the association; using robust adjustment for clustering of the outcome within one institute. The level of significance was set at $5 \%$ level. 


\section{Results}

\section{Background characteristics of study participants}

From the medical group, 275 ( $91.7 \%$ of the estimated sample) as compared to 299 ( $99.7 \%$ of the estimated sample) from the non-medical undergraduates filled-in the questionnaires. Table 1 summarizes some of the background information between the two groups. Male undergraduates were dominant in both groups, all group members were relatively young (less than 24 years) and the majority (more than $85 \%)$ were the never married.

\section{Modifiable risk factors associated for NCDs}

In figure 1 we present the proportion of undergraduates in medical and non-medical programmes for each of the five categories of modifiable risk factors for NCDs.

\section{Tobacco use}

Current tobacco use was 17 (3.0\%) among all undergraduates and 11 (4.2\%) among undergraduates in non-medical programmes as compared to $6(1.9 \%)$ students in non-medical programmes.

\section{Harmful alcohol consumption}

Among all undergraduates, 21 (3.7\%) reported consuming high risky alcohol. Although proportionately more than twice, 15 (4.8\%), medical undergraduates reported consuming high risky alcohol than nonmedical undergraduate students, $6(2.3 \%)$, the difference was not statistically significant.

\section{Unhealthy diet}

The proportion of undergraduates having unhealthy diet was $546(95.1 \%)$. Out of 315 undergraduates in medical programmes, 296 (94.0\%) reported having inadequate unhealthy diet as compared to 250 $(96.5 \%)$ of the 259 students in non-medical undergraduate programmes.

\section{Salt intake}

Out of 528 undergraduates, 21 (4.0\%) were affirmative having excessive salt intake. Excessive salt intake was higher among undergraduates in non-medical programmes as compared to their counterparts, 12 $(5.3 \%)$ against $9(3.0 \%)$ respectively.

\section{Physical inactivity}

Sedentary life among undergraduates in Dar es Salaam was in 179 (31.2\%). Significantly more undergraduates, $(p<0.01)$, in non-medical programmes were having sedentary life as compared to undergraduates in medical programmes, 97 (37.5\%) against $82(31.2 \%)$ respectively.

\section{Overall risky behaviours in medical and non-medical undergraduates}


The proportion of high risky behaviours among all undergraduate was $168(31.8 \%)$. High risk behaviours was significantly higher, 83 (36.6\%), among non-medical undergraduates as compared to $85(28.2 \%)$ in medical undergraduates $(p=0.042)$. In Table 2 we present correlates of modifiable high risk factors for NCDs among undergraduates. Undergraduates in medical programmes had $60 \%$ increased proportion for modifiable high risk as compared to undergraduates in non-medical programmes adjusting for sex and age group, (aPR=1.1, 95\% Cl: 1.0-1.2).

\section{Discussion}

The main objective of this study was to determine the burden of modifiable risk factors of NCDs among undergraduates in one city in Tanzania. The increasing prevalence of NCDs in all populations specifically in low and middle income countries is worrisome [22]. While one would expect education to have a significant positive impact on the practices in preventing NCDs, the outcomes are questionable [23].

In this study, the overall proportion of undergraduate using tobacco was less than $5 \%$ and almost similar among undergraduates in each of the sub-samples. During this decade, the proportion of smoking in the general population of adolescents in Dar es Salaam was also 4\% [24].

Low proportion of tobacco use may be difficult to explain. Nevertheless, concealment of tobacco use is also possible. However, earlier discussion about low tobacco use was based on a gain on knowledge about increasing risks for lung cancer, removal of free marketing of tobacco products and other social awareness could explain low prevalence of tobacco use [25]. Similarly, harmful alcohol consumption among all undergraduates was less than $5 \%$. This proportion is quite low as compared to a level of almost $10 \%$ and over $30 \%$ among University students in Ethiopia and Nigeria respectively [26, 27]. In these studies, the man reported key drivers, that could also be valid in our study, include peer pressure and some socio-economic factors.

Unhealthy dietary habits have serious consequences to the progress of university students and even in their subsequent life. In this study, many undergraduates, irrespective of their degree programmes, report experiencing unhealthy diets. Barriers to access healthy diet are classified into individual, social and institutional. In our case, individual factors leading to failure to take fruits could be poor income and unavailability of fruits in cafeteria menu.

In our study, physical inactivity among university students is about $30 \%$ and more often among undergraduates in medical programmes than the non-medical. Recently, possible sources of sedentary life were discussed by Ssewanyana et al. among adolescents in Kenya [28]. The current life style that puts young adults, specifically those in higher learning institutions include use of socio-media and television watching.

One of the limitations in the current study is the low response rate as a cost of using a questionnaire [29]. It was very difficult to make a close follow-up to have a complete return of the filled-questionnaires from respondents in the sampled non-medical universities. Despite our efforts on emphasizing the return of the 
tools, the overall response rate of more than $95 \%$ that was close to the estimated sample size was probably enough to give the desired power of the study.

Furthermore, assessing the burden of modifiable risk factors for NCDs using a WHO standard tool may have some limitations. Although the tool has been previously validated [30], we were not able to assess how undergraduates shared correct information for each component of the tool. For example, assessing time of physical inactivity using the STEP-I tool may have not been exhaustive. Nevertheless, for comparison purposes, STEP-I remains the best tool of choice. The current study marks a good contribution in literature of modifiable risk factors of NCDs among undergraduate students in the region.

In addition, STEP-I is complimented by STEP-II and STEP-III. In this study, due to limited resources, we were not able to include the other parts of the entire tool. Lack of two parts may have hampered the WHO STEPS methodology in assessing the modifiable risk factors for NCDs.

\section{Conclusion}

Specific modifiable risk factors of NCDs such as tobacco use, harmful alcohol consumption and salt intake were low regardless of the enrolled programmes. But the proportion of students having unhealthy diet and physical inactivity were extremely high especially among undergraduates in medical programmes. Students in medical programmes have $60 \%$ prevalence ratio higher than those in nonmedical programmes. Despite a caution when making inference from this study, we recommend universities and colleges to minimize sedentary life by setting aside mandatory time for physical exercises and to sensitize students about healthy diets within the brackets of their financial capabilities.

\section{Declarations}

\section{Ethics approval and consent to participate}

Although no human or animal samples were included in the research presented in this article, Muhimbili University of Health and Allied Institutional Review Board granted the ethical clearance number DA.282/298/01.c/. We also requested an oral informed consent from each of the study participants.

\section{Consent for publication}

Not applicable

\section{Availability of data and materials}

Although we collected data for this study based on adult consenting university students and assured them of confidentiality, we did not alert them for possible sharing of data by the third party. Therefore, it may not be possible to make these data a public consumable.

\section{Competing interests}


Authors declare that they have no competing interests.

\section{Funding}

Muhimbili University of Health and Allied Sciences (MUHAS) supported this study.

\section{Authors' contributions}

SA conceptualized the study, SA and MK designed the study, SA collected and processed the data, SA and MK analyzed data, drafted and reviewed the manuscript.

\section{Acknowledgements}

Authors thank all University students who consented to participate in this study. We thank MUHAS for financial support to carry out this study

\section{Abbreviations}

Cl: Confidence Interval; HCWs: Health Care Workers; MUHAS: Muhimbili University of Health and Allied Sciences; NCDs: Non-communicable diseases; PR: Prevalence ratio; STEPS: Stepwise approach to Surveillance; WHO: World Health Organization

\section{References}

1. World Health Organization (WHO). Noncommunicable diseases 2018. Available: http://www.who.int/news-room/fact-sheets/detail/noncommunicable-diseases. (Accessed: 13 July 2018).

2. World Health Organization (WHO). Global status report on noncommunicable diseases. 2014; 176, 2014.

3. World Health Organization (WHO). Global status report on non-communicable Diseases 2010. 2011; $9-31$.

4. Ministry of Health and Social Welfare, National Institute for Medical Research, World Health Organization. Tanzania Steps Surveys Report. 2013; 1-154.

5. Ministry of Health Zanzibar 2012. Zanzibar National NCD risk factor survey 2011. Zanzibar, Tanzania. 2012; 3 http://41.73.201.42/hmisnews/?cat=1252-4.

6. Kamau EN. Attitudes and practice of health promotion for non-communicable diseases among healthcare workers at Kenyatta National Hospital. A dissertation of Master of Public Health, School of Public Health, University of Nairobi. 2017.

7. Abramson S, Stein J, Schaufele M, Frates, Rogan S. Personal exercise habits and counseling practices of primary care physicians: a national survey. Clin. J. Sport Med. 2000; 10 (1):40-8. 
8. Yeravdekar RC, Yeravdekar VR. Healthcare delivery systems at higher educational institutions in India. Int J Prev Med. 2014;5(9):1203-1209.

9. Mishra SR, Neupane D, Shakya A, Adhikari S, Kallestrup P. Modifiable risk factors for major noncommunicable diseases among medical students in Nepal. J. Community Health. 2015; 40(5):863-8.

10. Silliman K, Rodas-Fortier K, Neyman M. A survey of dietary and exercise habits and perceived barriers to following a healthy lifestyle in a College population. Californian J. Health Promot. 2004; 2(2):109.

11. Grassi MC, Chiamulera C, Baraldo M, Culasso F, Ferketich AK, Raupach T, et al., Cigarette smoking knowledge and perceptions among students in four Italian Medical Schools. Nicotine Tob. Res. 2012; 14 (9): 1065-72.

12. Nyanjau L. Prevalence of behavioral risk actors of non-communicable diseases among postgraduate students at the University of Nairobi. A dissertation of Master of Public Health, School of Public Health, University of Nairobi. 2016.

13. Beck M. Checking Up on the Doctor. What Patients Can Learn From the Ways Physicians Take Care of Themselves. 2010. Available: https://www.wsj.com/articles/SB10001424052748704113504575264364125574500. (Accessed: 17 July 2018).

14. McGrady FP, McGlade KJ, Cupples ME, Tully MA, Hart N, Steele K. Questionnaire survey of physical activity in general practitioners (PHIT GP study). Ulster Med. J. 2007; 76(2): 91-7.

15. Al Alwan I, Badri M, Al-Ghamdi M, Aljarbou A, Alotaibi H, Tamim H. Prevalence of self-reported cardiovascular risk factors among Saudi Physicians: A comparative study. Int. J. Health Sci. 2013;7(1): 3-13.

16. Van Den Berg VL, Okeyo AP, Dannhauser A, Nel M. Body weight, eating practices and nutritional knowledge amongst university nursing students, Eastern Cape, South Africa. African J Prim Heal Care Fam Med. 2012; 4(1): 1-9.

17. Kunene SH, Taukobong NP. Dietary habits among health professionals working in a district hospital in KwaZulu-Natal, South Africa. Afr J Prim Health Care Fam Med. 2017;9(1):e1-e5. Published 2017 Jun 28. doi:10.4102/phcfm.v9i1.1364.

18. Mahmood S, Najjad MKR, Ali N, Yousuf N, Hamid Y. Predictors of obesity among post graduate trainee doctors working in a tertiary care hospital of public sector in Karachi, Pakistan. J. Pak. Med. Assoc. 2010; 60(9): 758-61.

19. Gandhi H, Prem VKV, Vijayakumar K, Adikari P, UnniKrishnan B. ASurvey on physical activity and noncommunicable disease risk factors among physicians in tertiary care hospitals. Natl. J. Community Med. 2012; 3(1): 7-13.

20. Sebo P, Bouvier Gallacchi M, Goehring C, Künzi B, Bovier PA. Use of tobacco and alcohol by Swiss primary care physicians: a cross-sectional survey. BMC Public Health. 2007;7:5. Published 2007 Jan 
12. doi:10.1186/1471-2458-7-5.

21. World Health Organization (WHO). STEPS instrument for NCD risk factors (core and expanded version 1.4). Geneva. 2008. Available: http/www.who.int/chp/steps/manual/en/index5.html. (Accessed on 22 June, 2018).

22. Gowshall M, Taylor-Robinson SD. The increasing prevalence of non-communicable diseases in lowmiddle income countries: the view from Malawi. Int J Gen Med. 2018;11:255-264.

23. Singh A, Bassi S, Nazar GP, et al. Impact of school policies on non-communicable disease risk factors - a systematic review. BMC Public Health. 2017;17(1):292.

24. Kapito-Tembo A, Muula AS, Rudatsikira E, Siziya S. Smoking among in-school adolescents in Dares Salaam, Tanzania: results from the Global Youth Tobacco Survey. Tanzania Journal of Health Research. 2011;(13(3):196-204.

25. Oredein T, Foulds J. Causes of the decline in cigarette smoking among African American youths from the 1970s to the 1990s. Am J Public Health. 2011;101(10):e4-e14. doi:10.2105/AJPH.2011.300289.

26. Mekonen T, Fekadu W, Chane T, Bitew S. Problematic Alcohol Use among University Students. Front Psychiatry. 2017;8:86. Published 2017 May 19. doi:10.3389/fpsyt.2017.00086.

27. Ajayi Al, Owolabi EO, Olajire OO. Alcohol use among Nigerian university students: prevalence, correlates and frequency of use. BMC Public Health. 2019;19(1):752. Published 2019 Jun 13. doi:10.1186/s12889-019-7104-7.

28. Ssewanyana D, Abubakar A, van Baar A, Mwangala PN, Newton CR. Perspectives on Underlying Factors for Unhealthy Diet and Sedentary Lifestyle of Adolescents at a Kenyan Coastal Setting. Front Public Health. 2018;6:11. Published 2018 Feb 9. doi:10.3389/fpubh.2018.00011.

29. Jones TL, Baxter MA, Khanduja V. A quick guide to survey research. Ann R Coll Surg Engl. 2013;95(1):5-7. doi:10.1308/003588413X13511609956372.

30. Au TB, Blizzard L, Schmidt M, Pham LH, Magnussen C, Dwyer T. Reliability and validity of the global physical activity questionnaire in Vietnam. J Phys Act Health. 2010;7(3):410-8.

\section{Tables}

Table 1. Background characteristics of study participants 


\begin{tabular}{|c|c|c|c|}
\hline & $\begin{array}{l}\text { Medical } \\
(\mathrm{n}=315)\end{array}$ & $\begin{array}{l}\text { Non-medical } \\
\quad(n=259)\end{array}$ & $\begin{array}{c}\text { Total } \\
(n=574)\end{array}$ \\
\hline Characteristics & Number (\%) & Number (\%) & $\begin{array}{c}\text { Number } \\
(\%)\end{array}$ \\
\hline \multicolumn{4}{|l|}{ Sex } \\
\hline Male & $204(64.8)$ & $172(66.4)$ & $376(65.5)$ \\
\hline Female & $111(35.2)$ & $87(33.6)$ & $198(34.5)$ \\
\hline Age group (years); mean & $24.1(2.2)$ & $23.6(2.5)$ & $23.8(2.3)$ \\
\hline (SD) & $230(73.0)$ & $197(76.1)$ & $427(74.4)$ \\
\hline $19-24$ & $85(27.0)$ & $62(23.9)$ & $147(25.6)$ \\
\hline \multicolumn{4}{|l|}{$25-49$} \\
\hline Marital status & $275(87.3)$ & $236(91.1)$ & $511(89.0)$ \\
\hline Never married & $25(7.9)$ & $18(6.9)$ & $43(7.5)$ \\
\hline Currently married & $15(4.8)$ & $5(2.0)$ & $20(3.5)$ \\
\hline Previously married & & & \\
\hline
\end{tabular}

Table 2. Correlates of modifiable high risk factors for NCDs

\begin{tabular}{lcrr}
\hline \multirow{2}{*}{ Correlate } & Number at high risk (\%) & Anadjusted & Pdjusted \\
\hline Type of University/College & & & \\
Non-medical & $83(36.6)$ & $1.1(1.0,1.2)$ & $1.1(1.0,1.2)$ \\
Medical & $85(28.2)$ & Reference & Reference \\
Sex & & & \\
Male & $99(28.9)$ & Reference & Reference \\
Female & $69(37.3)$ & $1.5(1.0,2.1)$ & $1.1(1.0,1.2)$ \\
Age group (years) & & & \\
$19-24$ & $133(33.5)$ & $1.4(0.9,2.1)$ & $1.1(1.0,1.2)$ \\
$25-49$ & $35(26.7)$ & Refernce & Reference \\
\hline
\end{tabular}

* Prevalence ratio (95\% Confidence Interval)

\section{Figures}




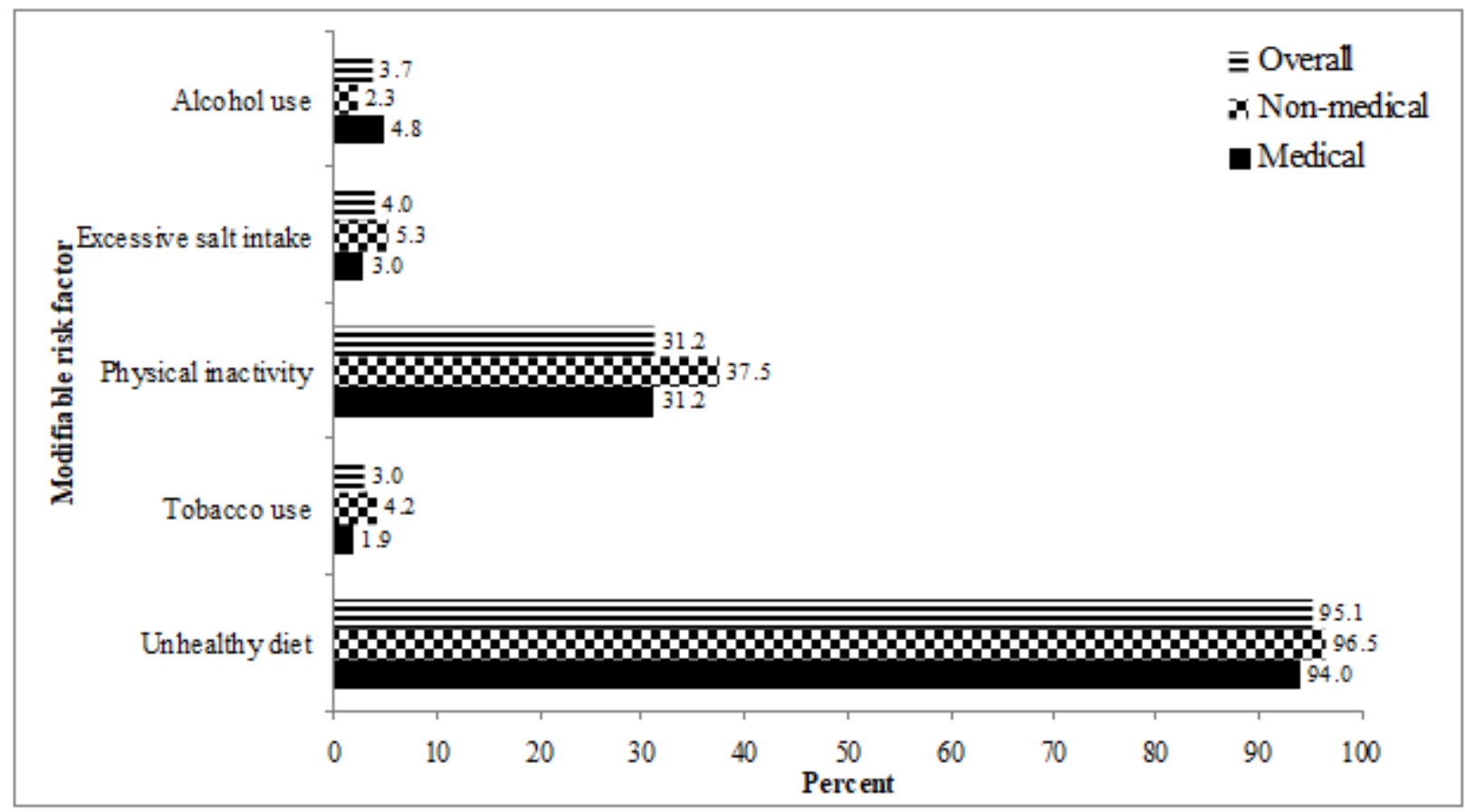

\section{Figure 1}

The proportion of medical and non-medical undergraduates reporting modifiable risk factors for NCDs 